\title{
Forecasting of Wind Induced Pressure on Setback Building Using Artificial Neural Network
}

\author{
Amlan Kumar Bairagi ${ }^{1 *}$, Sujit Kumar Dalui ${ }^{1}$ \\ ${ }^{1}$ Civil Engineering Department, Engineering Faculty, Indian Institute of Engineering Science and Technology, Shibpur, Howrah, \\ West Bengal, 711103, India \\ * Corresponding author, e-mail: amlan.bairagi.rs2016@civil.iiest.ac.in
}

Received: 15 February 2020, Accepted: 30 April 2020, Published online: 28 May 2020

\begin{abstract}
The wind load on an irregular plan shape tall building is quite different compared to a conventional plan shape tall building. Especially the aerodynamic parameters have extreme change due to the variety of setbacks at one or more the disparity of level. This paper highlights the prediction of pressure coefficient on square, single (20\%) setback and double (10\%) setback buildings for any wind incidence angle by CFD simulation and validated with Artificial Neural Network (ANN) and fast Fourier transform. The ANN is a widely used and efficient tool for different types of analyses. The $0^{\circ}$ to $180^{\circ}$ wind incidence angles (WIAs) considered as input data and respective face wise pressure coefficient $\left(C_{p}\right)$ used as target data. The Levenberg-Marquardt training function and Mean Square Error (MSE) performance function used to train the target data. The face wise graphs of CFD, ANN and FFT are plotted in a single graph and the $C_{p}$ of the surface checked by any random WIAs. Amazingly, the $C_{p}$ of random WIA by ANN is almost similar to CFD. Furthermore, the error of ANN is $0.6 \%$ to $2.5 \%$, which is negligible. According to this predicted graph, the design $C_{p}$ of any WIA can be easily calculated and implement directly in the design.
\end{abstract}

Keywords

pressure coefficient, drag, lift, artificial neural network (ANN), setback tall building

\section{Introduction}

Wind flow around the unconventional shape, tall buildings are quite different compared to the uniform plan shape tall buildings. The wind pressure on the wall and the roof of an unconventional tall building has a huge difference concerning regular plan shape tall building. The number of setbacks also take an important part on pressure variation on wall. Kim et al. [1] studied high-frequency force balance wind tunnel tests on the square, setback and the tapper model and suggested the across wind acceleration of a setback and tapper model was higher than the square model. Tanaka et al. [2] covered twenty-eight numbers of different unconventional tall buildings in closed-circuit type wind tunnel to determine the aerodynamic forces, and wind pressures. Bairagi and Dalui [3] investigated the optimum distance on parallel high-rise buildings where the interference effects nullify with different orientations using CFD. The number of researchers (Roy and Kumar Bairagi [4], Elshaer et al. [5], Cui and Caracoglia [6], Li et al. [7], Bairagi and Dalui [8-10], Rajasekarababu et al. [11]) already studied the wind load on unconventional tall buildings by LES, $k-\varepsilon$ methods and estimated the effects of spectral density, moment, drag, and lift coefficients on different face and rooftop of the buildings. Bitsuamlak et al. [12] found the combined CFD and numerical-neural network (NN) approach and to speeded-up the ratios for a wide range of topographic features like single and multiple hills, escarpments, and valleys. Wang and Cheng [13] determined wind spectra on rectangular cross-section buildings by the ANN method. There have been many researches on setback tall buildings and most of them are symmetry about two axes. Verma et al. [14] determined the wind pressure coefficients on the windward face of $30 \mathrm{~m} \times 30 \mathrm{~m} \times 180 \mathrm{~m}$ tall building by Back Propagation Neural Network (BPNN) and compared the data with the experimental result. Elshaer et al. [15] presented the aerodynamic shape optimization procedure on CFD, optimization algorithm and Artificial Neural Network (ANN). The 200 input data used to train the network and evaluated the objective function. The study covered two optimization problems. Problem 1 used to find the optimal 
tall building cross-section to reduce the drag force due to wind and problem 2 used to found the optimal cross-section to reduce the wind lateral vibration. The optimization tool already takes a large role and used to predict the interference effect minimization (Kar et al. [16]), folded curve plate design (Balogh and Lógó [17]), truss optimization with multiple natural frequency constraints (Kaveh and Kooshkbaghi [18]) and many multi-disciplinary types of researches. Dhote and Varghese [19] analyzed the bending moment and shear force variation on tall buildings by ANN method, and validated with IS 875 (Part-3) [20]. Elshaer and Bitsuamlak [21] optimized the aspect ratio and opening distances between different rectangular slot type buildings. The prototype models are studied by the CFD package of STAR CCM+, employed the LES method, and validated with the ANN method simultaneously. Bahattacharyya and Dalui [22] introduced the graphical method to estimate the pressure coefficient on 'E' plan shape tall building. The researchers studied the face pressure coefficients at any intermediate wind angle by Fast Fourier series and validated with wind tunnel data. The present study suggests the face pressure coefficient at any intermediate wind angle by using both the fast Fourier series and Artificial Neural Network (ANN) method. The ANNs is a multi-disciplinary as well as user-friendly system and presently use in different engineering and technological regions. Kaveh and Iranmanesh [23] compared the backpropagation neural net (BPN) and the improved counter propagation neural net $(\mathrm{CPN})$ to the analysis and design of large-scale space structures. Iranmanesh and Kaveh [24] presented the neurocomputing strategy, which combines the data processing capabilities of neural networks and numerical structural optimization. Kaveh and Khalegi [25], Kaveh et al. [26], Rofooei et al. [27] studied the concrete specimen and concrete moment resisting frame structure by backpropagation of neural network. A Paral et al. [28] introduced the ANNs to identify the structural damage in share frame building. The number of researchers (Kaveh and Servati [29], Kaveh et al. [30], Fernández-Cabán et al. [31], Nikose and Sonparote [32, 33], Mallick et al. [34]) already applied the neural network in the different field of studies likes grid base structure, transmission tower design, predict the magnitude and roof pressure, the dynamic-wind response on high rise buildings. Not only that the optimal shape of the building also found by the ANN method. This paper highlights the estimation of pressure coefficient at any angle of single and double setback tall building by Computational Fluid Dynamics (CFD) and validated with
ANN and FFT method. Furthermore, the pressure coefficients at a different surface of any intermediate wind angle can easily be estimate by the graph.

\section{Description of model}

Three sets of models considered in this study. One regular square plan shape building, and two setback buildings. All the buildings have the same ratio of length: breadth: height (1:1:2). The three models are shorted as M1, M2, and M3. The M1 model considered as regular square plan shape model. The M2 model has $0.2 \mathrm{~L}$ (20 \%) setback distance at the $\mathrm{H} / 2$ level and the M3 model has two 0.1L (10 \%) setbacks at $\mathrm{H} / 3$ and $2 \mathrm{H} / 3$ level. Where $\mathrm{H}$ is the height of the model and $\mathrm{L}$ is the length of the model. In this connection, the summation of the setback area and roof top area of the M2 and M3 models are same as the roof top area of M1 model. Therefore, the total roof area including top and setback roof of the entire models are same. The models M2 and M3 have symmetry about a single plane (YZ), therefore wind incidence angles (WIAs) are considered as $0^{\circ}, 15^{\circ}, 30^{\circ}, 45^{\circ}, 60^{\circ}, 75^{\circ}, 90^{\circ}, 105^{\circ}, 120^{\circ}, 135^{\circ}, 150^{\circ}, 165^{\circ}$, and $180^{\circ}$. The along wind considered in Y-axis and across wind in $\mathrm{X}$-axis. The adopted windward faces are $\mathrm{A}$ and $\mathrm{D}$ for the $\mathrm{X}$-axis and Y-axis, respectively. Similarly, the leeward faces are $\mathrm{C}$ and $\mathrm{B}$ for the same respective axes. The single setback model (M2) has two different roofs (R1 and R2) and different faces are D1 and D2. Similarly, the double setback model (M3) has three different roofs (R1, $\mathrm{R} 2$, and R3) and three faces are D1, D2, and D3. The D1, D2 and D3 faces of M2 and M3 models are considered as "Face D" to minimize the complicacy. The respective face names and WIAs of the models are shown in Fig. 1.

\section{Numerical method}

The $k$ - $\varepsilon$ turbulence model is the most widely used in the fluid dynamic scenario. Jones and Launder [35] first introduced this model and determined the turbulence viscosity significantly by local values of density, turbulence kinetic energy $(k)$ and turbulence length scale $(l)$ to fix up the uniform dimension and expressed in Eq. (1).

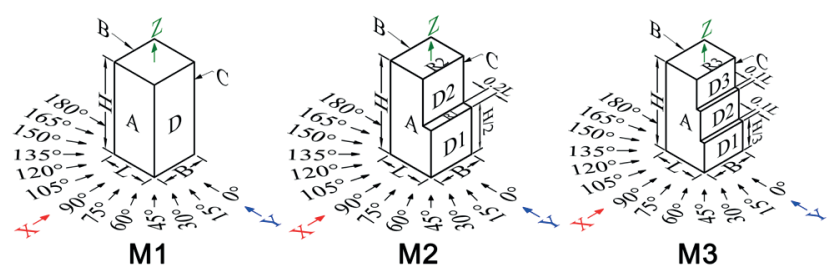

Fig. 1 Conventional square model (M1), single setback model (M2) and double setback model (M3) with different WIAs used in the present study 
$\mu_{t}=C_{\mu}^{\prime} \rho l k^{0.5}$

where, $\mu_{t}$ and $k$ is nonzero, $\rho$ is fluid density $C_{\mu}^{\prime}$ is a constant. The equation of turbulence energy accessed by a scalar product of momentum equation and velocity vector and it may be articulated as in Eq. (2).

$\rho \frac{D k}{D t}=\frac{\partial}{\partial y}\left(\frac{\mu_{t}}{\sigma_{k}} \frac{\partial k}{\partial y}\right)+\mu_{t}\left(\frac{\partial u}{\partial y}\right)^{2}-\rho \varepsilon$

and the equation of energy dissipation in Eq. (3).

$\rho \frac{D \varepsilon}{D t}=\frac{\partial}{\partial y}\left(\frac{\mu_{t}}{\sigma_{k}} \frac{\partial \varepsilon}{\partial y}\right)+C_{1} \frac{\varepsilon}{k} \mu_{t}\left(\frac{\partial u}{\partial y}\right)^{2}-C_{2} \frac{\rho \varepsilon^{2}}{k}$

The $\varepsilon$ may be assumed proportional to $\rho k^{1.5} / l$ for higher amount of Reynolds number. Thus, the Eq. (1) may be replaced in Eq. (4).

$\mu_{t}=\frac{C_{\mu} \rho l k^{2}}{\varepsilon}$

The turbulence model constants are $C_{\mu}=0.09, C_{1}=1.55$, $C_{2}=2.0, \sigma_{k}=1.0, \sigma_{\varepsilon}=1.3$.

\section{Analytical setups}

\subsection{Boundary condition}

Computation Fluid Dynamics (CFD) simulation is a widely accepted method for analytical study. This study, based on CFD simulation, where the analytical models are placed inside the domain. The inlet and sidewalls of the domain fixed at $5 \mathrm{H}$ from the extreme edge of the model and outlet wall considered at $15 \mathrm{H}$ for the model. The domain height is $6 \mathrm{H}$ from the bottom of the model as directed by Franke et al. [36] and Revuz et al. [37]. The velocity of the fluid at the wall boundary is set to zero and no-slip condition for the model wall. The Power law used to calculate the velocity profile of the atmospheric boundary layer as per SP 64 (S\&T) [38] and IS 875 (Part 3) [20]. The equations of power-law and turbulence intensity as shown in Eqs. (5-6), respectively.

$$
\frac{U_{z}}{U_{R}}=\left(\frac{Z}{Z_{R}}\right)^{\alpha}
$$

$I=\frac{u^{\prime}}{U}=\frac{\sqrt{\frac{2}{3} k}}{U}$

where $U_{z}$ is the horizontal wind speed at an elevation $Z$; $U_{R}$ is the speed at the reference elevation $Z_{R}$; which was $10 \mathrm{~m} / \mathrm{s} ; \alpha$ is the power-law index $(0.133)$ for Category 2 , $Z_{H}$ is $1.0 \mathrm{~m}$. $k$ is the turbulence energy, $u^{\prime}$ is the root mean square of turbulence velocity and $U$ is the mean velocity.

\subsection{Computational mesh and grid}

Tetrahedron meshing used in this study and fine discretized mesh also used for satisfactory results. The dimension of the computational domain used in this study is $10.25 \mathrm{~m} \times 5.25 \mathrm{~m} \times 3.0 \mathrm{~m}$. The blockage ratio in this study is $0.4 \%$, which is less than the recommended value of Franke et al. [39] and Tominaga et al. [40]. Large, coarse, medium, and fine grids are used in this analytical study, namely GR1, GR2, GR3, and GR4, respectively. The initial grid of domain considered as 5.21 million elements and finally fixed with 12.51 million elements. The variation of pressure $\left(C_{p}\right)$, force $\left(C_{f}\right)$ and moment $\left(C_{m}\right)$ coefficients according to the variation of grid sizes shown in Table 1 . The values of $C_{p}, C_{f}$ and $C_{m}$ converge in the fine grid size of the domain. Finally, the fine grid size of the domain considered for further study.

\subsection{Validation of analytical study}

\subsubsection{Comparison of flow characteristics with the previous study}

The similar type of model studied by Bairagi and Dalui [8] and validated the CFD simulation of pressure and force coefficient with Australia/New Zealand standard, American standard, European standard, British standard, and Indian standard codes. Furthermore, the present analytical study also validated with an experimental study by Kim and Kanda [41]. The experiments conducted by Eiffeltype wind tunnel at the University of Tokyo. The tunnel section was $1.8 \mathrm{~m} \times 1.8 \mathrm{~m}$ and $12.5 \mathrm{~m}$ in length. The experimental model was $L \times B \times H=100 \mathrm{~mm} \times 100 \mathrm{~mm} \times 400$ $\mathrm{mm}$ of length scale $1 / 400$ and $\alpha=0.13$. The blockage ratio was $1.2 \%$ with wind flow at $6.5 \mathrm{~m} / \mathrm{s}$. A square prism placed

Table 1 Components of computational grids

\begin{tabular}{|c|c|c|c|c|c|c|c|c|}
\hline Mesh quality & Grid mark & Element & Windward $C_{p}$ & $\%$ of error & $C_{f}$ & $\%$ of error & $C_{m}$ & $\%$ of error \\
\hline Large & GR1 & 5210569 & 0.70 & 8.7 & 1.13 & 3.5 & 1.34 & 3.54 \\
\hline Coarse & GR2 & 11578493 & 0.74 & 3.0 & 1.15 & 1.6 & 1.37 & 1.6 \\
\hline Medium & GR3 & 12093078 & 0.77 & 0.05 & 1.17 & 0.02 & 1.38 & 0.01 \\
\hline Fine & GR4 & 12513045 & 0.77 & -- & 1.17 & -- & 1.39 & -- \\
\hline
\end{tabular}


in the analytical domain with the same aspect ratio as well as the same experimental constants with large to fine grid consideration. Finally, the GR4 grid serves the satisfactory results. Finally, the velocity and turbulence intensity compared with GR4 grid model and the experimental study by Kim and Kanda [41] as shown in Fig. 2(a). The power spectra at the top of the model shown in Fig. 2(b), which agree with the Karman type spectra.

\subsubsection{Comparison of the present study with past experimental data}

The non-dimensional turbulence kinetic profile and mean stream wise velocity on (1:1:2) (length:breadth:height) square plan shape analytical model further validated with Meng and Hibi [42] and Wang et al. [43]. The $80 \mathrm{~mm} \times 80 \mathrm{~mm} \times 160 \mathrm{~mm}(1: 1: 2)$ experimental model was studied by Meng and Hibi [42] and $2.64 \mathrm{~m} \times 0.9 \mathrm{~m} \times 0.9 \mathrm{~m}$ domain dimensions used by Wang et al. [43]. These experimental results also used by Tominga et al. [44] by the $k-\varepsilon$ model, Gosseau et al. [45] by the LES method and Wang et al. [43] by both Large Eddy Simulation (LES) and Combination Random Flow Generation (CRFG) method. The non-dimensional profile locations are considered $\mathrm{x} / \mathrm{b}=-0.75 ;-0.25 ; 0.5 ; 1.25$ and 3.25 as stated by Meng and Hibi [42]. However, in this study along wind direction considered on the $y$-axis. So, the profile locations are fixed at $y / b=-0.75 ;-0.25 ; 0.5 ; 1.25$ and 3.25 . In this case, the

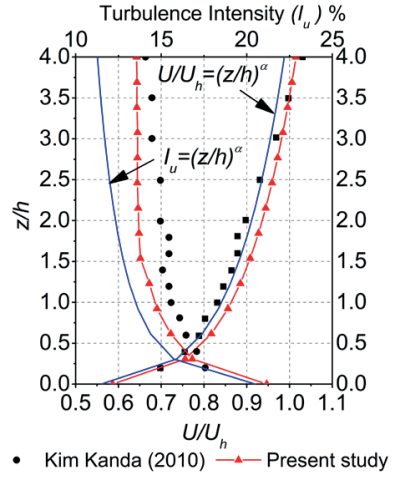

(a)

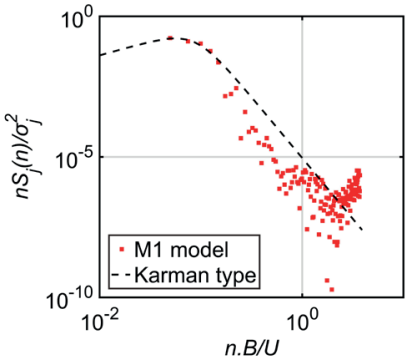

(b)
Fig. 2 (a) Comparative study of velocity and turbulence inside the domain with Kim and Kanda [41] and mathematical expression. (b) Power spectral density with Karman type expression

bluff body was placed inside the domain (Franke et al. [39] and Tominaga et al. [40]). The turbulence kinetic profile in Fig. 3(a) and mean stream wise velocity profile in Fig. 3(b)-(f) are displayed the comparison between experimental (EXP.), CRFG and $k-\varepsilon$ model. These figures acceptably acknowledged the EXP, CRFG and present $k-\varepsilon$ study of the bluff body. If anyone interested to know, the comparative study between EXP and LES method then refers to Gosseau et al. [45]. Because the study also has same experimental data. According to this validation, it said that the further analytical study of square model and setback models also produce authentic data.

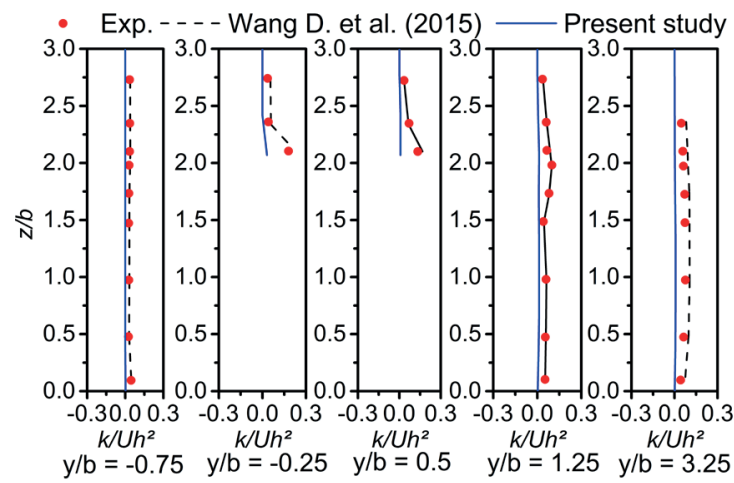

(a)

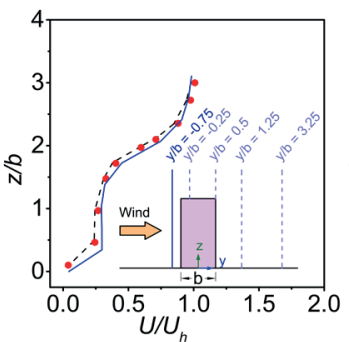

(b)

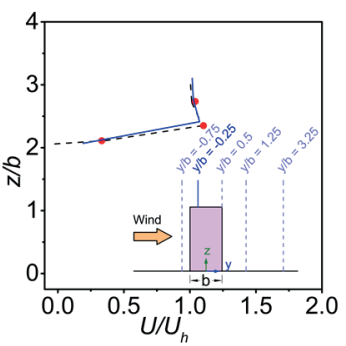

(c)

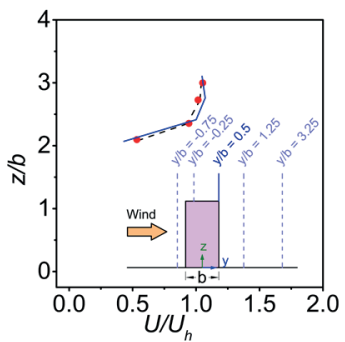

(d)

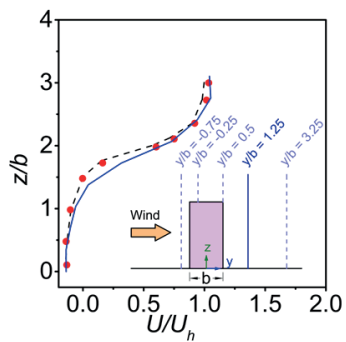

(e)

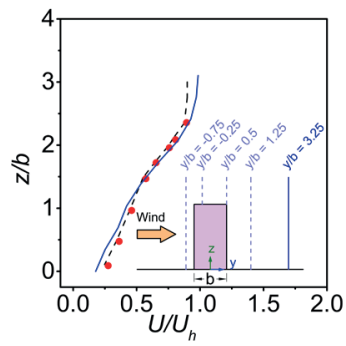

(f)

Fig. 3 Comparison of present study and experimental study (Meng and Hibi [42]) of (a) turbulence kinetic profile at y/b $=-0.75,-0.25,0.5,1.25,3.25$ and mean stream wise velocity profile at $\mathrm{y} / \mathrm{b}$, (b) -0.75 , (c) -0.25 , (d) 0.5 , (e) 1.25 , (f) 3.25 


\section{Analytical results}

\subsection{Kinetic turbulence and velocity profile}

The non-dimensional stream wise velocity profile at $\mathrm{y} / \mathrm{b}=-0.75,-0.25,0.5,1.25$, and 3.25 (Meng and Hibi [42] and Gosseau et al. [45]) observed for M1, M2, and M3 models. The vertical dotted lines placed at their respective $y / b$ locations. The positive values of $y / b$ fixed at the right side of the vertical dotted line and negative values placed on the left side of the same line. The building model placed at $y / b=0$ and along with wind flow considered from the $y$-axis. Fig. 4(a) represents the non-dimensional variation of velocity along $\mathrm{z} / \mathrm{b}=0$ to 3 (top of the domain) at different $\mathrm{y} / \mathrm{b}$ profiles. For the $0^{\circ}$ wind angle at $\mathrm{y} / \mathrm{b}=-0.75$ profile, an enormous amount $(41.27 \%$ at $\mathrm{z} / \mathrm{b}=1.38)$ of velocity fluctuation observed for M2 and M3 models compared with the M1 model. Again, at $y / b=-0.25$ location have $68.31 \%$ higher velocity observed on both M2 and M3 models.

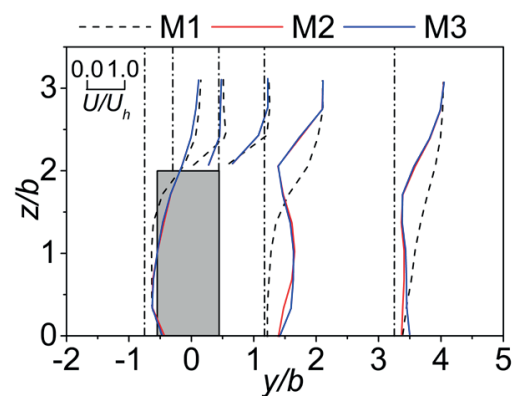

(a)

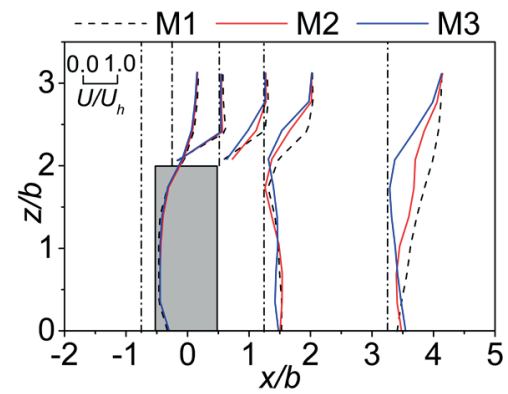

(b)

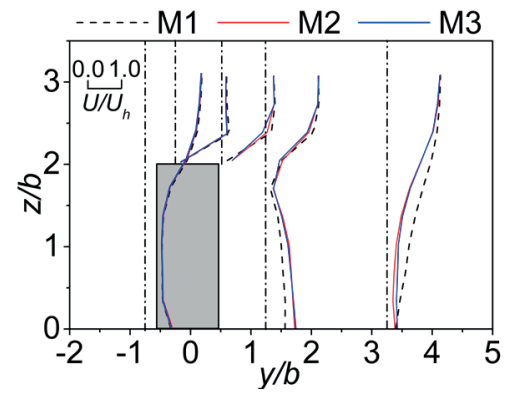

(c)

Fig. 4 Velocity profile comparison between M1, M2 and M3 models at $\mathrm{y} / \mathrm{b}=-0.75,-0.25,0.5,1.25$ and 3.25 for WIAs (a) $0^{\circ}$, (b) $90^{\circ}$ and (c) $180^{\circ}$
Nevertheless, an interesting velocity variation detected at the $y / b=1.25$ profile. In this profile, the maximum velocity difference observed at $\mathrm{z} / \mathrm{b}=1.03$ and 2.07 between $\mathrm{M} 1$ and M2 models. At the location $\mathrm{y} / \mathrm{b}=3.25$, have $26 \%$ less velocity compared to M1 model at $\mathrm{z} / \mathrm{b}=1.72$. Fig. 4(b) represents the velocity profile for $90^{\circ}$ WIA. The velocity gradually decreased at profile $\mathrm{y} / \mathrm{b}=0.5,1.25$ and 3.25 . At the profile $\mathrm{y} / \mathrm{b}=0.5$, the velocity decreased $18.8 \%$ on the M2 model compare to the M1 model and the model M3 has $36.3 \%$ less velocity at $z / b=2.41$. Similarly, at $\mathrm{y} / \mathrm{b}=1.25$ have $40.7 \%$ and $58.39 \%$ less velocity for M2 and M3 models, respectively. At the extreme profile at $\mathrm{y} / \mathrm{b}=3.25$, the maximum $56.6 \%$ velocity deflection observed on M3 model and $38.6 \%$ for M2 model at $\mathrm{z} / \mathrm{b}=2.07$. No conspicuous change of velocity observed at the profiles for $180^{\circ}$ wind as shown in Fig. 4(c). Only $43.4 \%$ velocity fluctuation noticed at $\mathrm{z} / \mathrm{b}=1.38$ for the $\mathrm{M} 2$ and M3 models.

\subsection{Concept of CFD, FFT and ANN}

\subsubsection{Computational Fluid Dynamics (CFD)}

The analytical value of the pressure coefficient $\left(C_{p}\right)$ calculated by CFD simulation. The Eq. (7) used to estimate the $C_{p}$ of windward, leeward, side face and rooftop of the models.

$$
C_{p}=\frac{P_{c a l}}{\frac{1}{2} \rho U_{z}^{2}}
$$

where, $P_{c a l}$ is the calculated pressure taken from simulation, $\rho$ is the density of air $\left(1.18 \mathrm{~kg} / \mathrm{m}^{3}\right.$ for $\left.25^{\circ} \mathrm{C}\right)$.

\subsubsection{Fast Fourier Transform (FFT)}

The mean pressure of different faces for the respective WIAs calculated by the FFT method. The curve fitting tools of MATLAB used to fit the $C_{p}$ at different WIAs by Fast Fourier Transform (FFT). The Fourier series expression represented by the sum of the series of sine and cosine functions. Equation (8) represents the Fourier series transform

$$
f(x)=\frac{a_{0}}{2}+\sum_{i=1}^{\alpha}\left(a_{i} \cos i \omega_{i} x+b_{i} \sin i \omega_{i} x\right),
$$

where $a_{0}, a_{i}, b_{i}$ are Fourier coefficients, $\omega_{i}$ is the frequency of the signal and represented by $2 \pi$ to the time period, $\alpha$ is the index starts with $i=1$ to infinity, $x$ is several wind incidences angles and $f(x)$ represents the mean face pressure. The number index is chosen for the proper harmonic polynomial start from 1 to 4 . Therefore, the expression of Fourier transforms for each face of the models is express in Eq. (9). 


$$
\begin{aligned}
& f(x)=a_{0}+a_{1} \cos \left(\omega_{1} x\right)+b_{1} \sin \left(\omega_{1} x\right) \\
& +a_{2} \cos \left(2 \omega_{2} x\right)+b_{2} \sin \left(2 \omega_{2} x\right)+\ldots \\
& +a_{4} \cos \left(4 \omega_{4} x\right)+b_{4} \sin \left(4 \omega_{4} x\right)
\end{aligned}
$$

The fitted curves attractively balanced with the analytical statistics. The statistical results of different errors also calculate in MATLAB. The sum of square due to regression $(S S R)$ in Eq. (10) has been estimated the slope of regression from the horizontal to the mean of the sample. The mathematical method of the sum of square error (SSE) in Eq. (11) used to calculate the best-fit function of the series of pressure coefficients for their respective WIAs. The value of the error is staying 0.0087 for M1, 0.035 for M2 and 0.014 for the M3 model. So, all the SSE values are appreciable for the analytical model. The total sum of square (SSTO) is the sum of SSR and SSE, which use to determine by the coefficient of determination $\left(R^{2}\right)$ in Eqs. (12-13). As the $R^{2}$ always between 0 to 1 , so that the analytical values are $<1$ for M1, M2, and M3 models. Therefore, the data of $C_{p}$ perfectly fall on the line of regression. Again, $R^{2}$ is simply the square of correlation coefficient $(R)$. The root mean square error (RMSE) in Eq. (14) calculate the number of errors for the sets of $C_{p}$ for M1, M2 and M3 models. The $R M S$ error range for the M1 model between 0.044 to 0.054 . Similarly, for M2 model has 0.108 for face A and 0.033 for face C. Again, the minimum error is 0.028 for face $\mathrm{A}$ and 0.068 for both $\mathrm{C}$ and $\mathrm{D}$ faces on M3 models. The correlation coefficients ranged from 0.94 to 0.999 , which seems high accuracy of the result.

$$
\begin{aligned}
& S S R=\sum_{i=1}^{N}\left(f\left(x_{i}\right)-\bar{y}\right)^{2} \\
& S S E=\sum_{i=1}^{N}\left\{y_{i}-f\left(x_{i}\right)\right\}^{2} \\
& S S T O=(\operatorname{SSR}+\operatorname{SSE})=\sum_{i=1}^{N}\left(y_{i}-\bar{y}\right)^{2} \\
& R^{2}=\frac{\operatorname{SSR}}{\operatorname{SSTO}}=1-\frac{\operatorname{SSE}}{\operatorname{SSTO}}=1-\frac{\sum_{i=1}^{N}\left\{y_{i}-f\left(x_{i}\right)\right\}^{2}}{\sum_{i=1}^{N}\left(y_{i}-\bar{y}\right)^{2}} \\
& R M S E=\sqrt{\frac{\sum_{i=1}^{N}\left\{y_{i}-f\left(x_{i}\right)\right\}^{2}}{N}}
\end{aligned}
$$

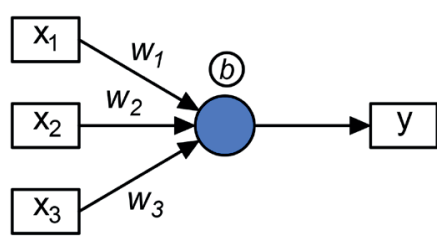

(c)

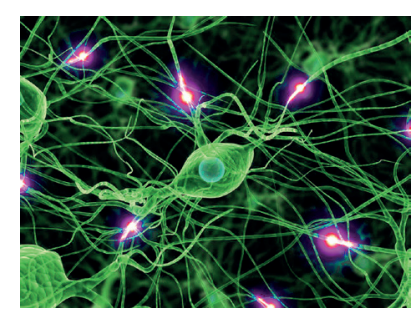

(b)

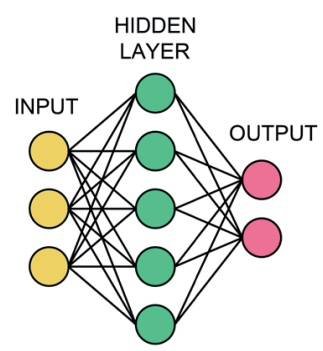

(d)
Fig. 5 (a) Biological neuron, (b) biological neuron network, (c) artificial neuron (d) artificial neural network 
The ANNs have three types of network architectures, single layer feed-forward networks, multilayer feed-forward networks, and recurrent networks. In single layer feed-forward networks, the neurons are formulated in the form of layers. The input layer of source node directly projects the signal to output layer of neurons or computational nodes but not conversely. The multilayer feed-forward network has one or more hidden layers. The hidden layers are not directly seen from either input or output of the network. The recurrent network has similarity with feed-forward network, but it has at least one feedback loop by which the output signal back to the input node of all other neurons (Haykin, [46]). The learning may be supervised or unsupervised feed-forward depending upon the topology of ANNs and the feed-forward neural network usually trained by supervised training procedures (Kaveh and Raissi Dehkorid [47]). The feed-forward with a single hidden layer network considered in this study. Three definite functional operations take place in this single neuron system. Demuth and Beale [48], Beale et al. [49] demonstrated the architecture of single and multiple input neuron systems shown in Fig. $6(\mathrm{a}-\mathrm{b})$. At first, the term $p$ is a scaler unit, which multiplied with scalar weight $w$ and forms a product $w_{p}$. Next, the weighted input $w_{p}$ is added with the scalar bias $b$ to develop a net input $n$. Finally, the net input $n$ cross through the transfer function $f$ which formed a scalar output $a$. The output of $a$ for single input system shown in Eq. (15).

$a=f(w p+b)$

These three processes called the weight function, the net input function and transfer function (Beale et al. [49]). For multiple input neurons have individual inputs $p_{1}, p_{2}$, $p_{3} \ldots p_{R_{i}}$ are weighted by $w_{1,1}, w_{1,2}, w_{1,3} \ldots w_{1, R_{i}}$ and formed a weight matrix $W$. The neuron bias $b$ summed with the weighted matrix and formed net input $n$ shown in Eq. (16).

$n=w_{1,1} p_{1}+w_{1,2} p_{2}+w_{1,3} p_{3}+\ldots+w_{1, R i} p_{R i}+b$

The expression of single neuron can be written in matrix form in Eq. (17).

$n=W p+b$

Therefore, the neuron output $a$ written in Eq. (18).

$a=f(W p+b)$

For $R_{i}$ number of input and $S_{i}$ number of neurons, the weighted matrix written in Eq. (19).
$\mathrm{W}=\left[\begin{array}{cccc}w_{1,1} & w_{1,2} & \ldots & w_{1, R i} \\ w_{2,1} & w_{2,2} & \ldots & w_{2, R i} \\ \ldots & \ldots & \ldots & \ldots \\ w_{S i, 1} & w_{S i, 2} & \ldots & w_{S i, R i}\end{array}\right]$

\section{ANN Method in pressure coefficient}

Three independent Artificial Neural Networks used to train the pressure coefficients $\left(C_{p}\right)$ at different faces of M1, $\mathrm{M} 2$, and M3 models according to the WIAs $0^{\circ}$ to $180^{\circ}$ at $15^{\circ}$ intervals. Therefore, 13 numbers of input data (WIAs) like $0^{\circ}, 15^{\circ}, 30^{\circ}, 45^{\circ}, 60^{\circ}, 75^{\circ}, 90^{\circ}, 105^{\circ}, 120^{\circ}, 135^{\circ}, 150^{\circ}$, $165^{\circ}, 180^{\circ}$ and 13 numbers of face wise target data $\left(C_{p}\right)$ are considered. The MATLAB package used in this study to train the ANN model by NNTOOL command. The power of neural networks depends upon the number of connections and the neural network architectures vary with the complexity and efficiency (Hunter et al. [50]). The neural network architecture for a single hidden layer and the flow diagram of the network as shown in Fig. 7(a)-(b) respectively. The feed-forward neural network used for the simple classification. In this method, the input data travel in a single direction and reach the output nodes via artificial neural nodes. In this condition, no backpropagation considered. The number of layers depends upon the complexity of the function (Haykin [46]). In this study only have 13 numbers of input and target data. Therefore, the feed-forward neural network is appropriate for this study.

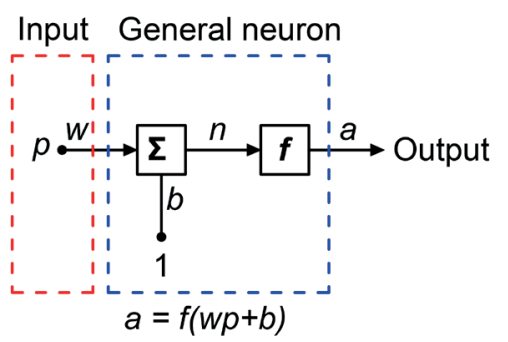

(a)

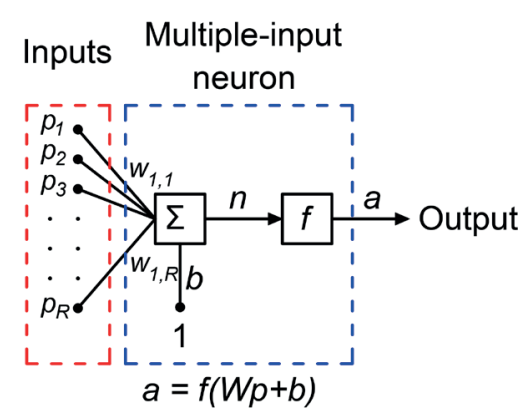

(b)

Fig. 6 (a) Single input neuron (b) multiple input neuron 


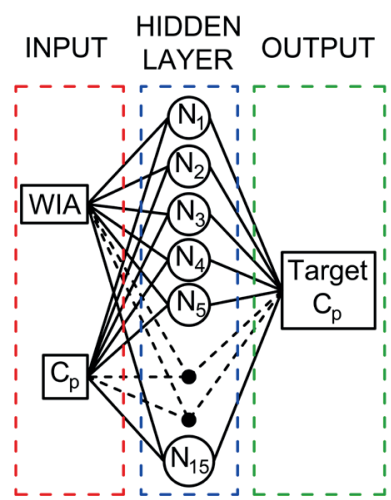

(a)

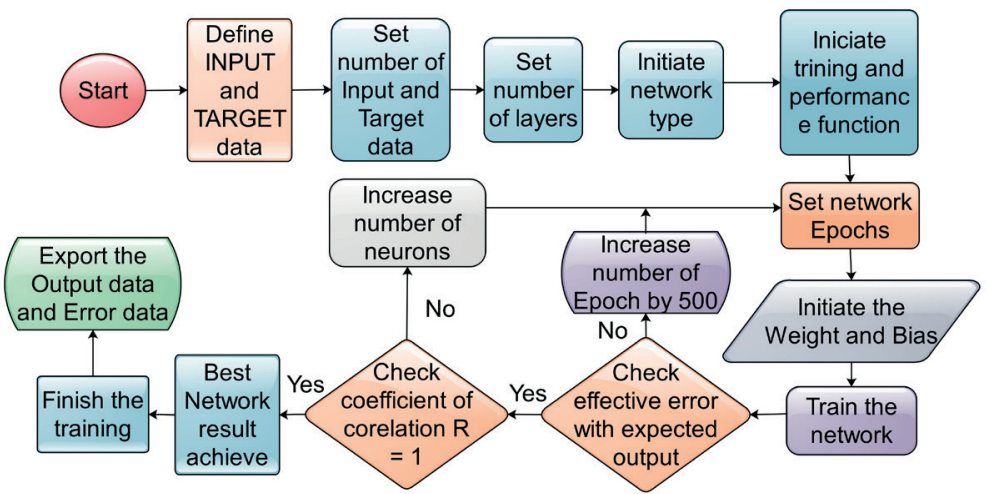

(b)

Fig. 7 (a) Single hidden layer neural network architecture and (b) flowchart of the artificial neural network training process

The single hidden layer considered due to little amount of data with the gradually increasing number of neurons from 5, 7, 10, 12 and 15. The Levenberg-Marquardt (TRAINLAM) training function and Mean Square Error (MSE) performance function used to train the target data. Initially, the train starts with 500 epochs and gradually increased the epoch numbers until the coefficient of correlation $(R)$ reach $0.99-1.0$.

\subsection{Comparison of pressure coefficient}

The pressure coefficient $\left(C_{p}\right)$ of different faces according to WIAs on M1, M2, and M3 models compared with CFD, FFT and ANN methods by MATLAB package. The models simulated inside the domain for $0^{\circ}, 15^{\circ}, 30^{\circ}$, $45^{\circ}, 60^{\circ}, 75^{\circ}, 90^{\circ}, 105^{\circ}, 120^{\circ}, 135^{\circ}, 150^{\circ}, 165^{\circ}$ and $180^{\circ}$ WIAs and the pressure coefficients are calculated by Eq. (7). Furthermore, the CFD results validated by the FFT method after that, the CFD results trained by the ANN model. The comparison of pressure coefficient on different faces for M1, M2, and M3 models are showcased in Figs. 8-10. The top and bottom dotted lines represent the $95 \%$ prediction bound of the FFT results. The coefficient of correlation $(R)$ of neural network training presents an appreciable value of 0.99998 . Fig. 11 presents the comparison of $R$ between FFT and ANN method on different faces of M1, M2 and M3 models. The correlation coefficient by FFT on face $\mathrm{C}$ has the highest variation than the ANN method. It seems that the ANN results are more accurate compared to the FFT results. Now it is time to check the pressure coefficient at an intermediate angle except the considered one. Therefore, two intermediate WIAs $25^{\circ}$ and $145^{\circ}$ considered and simulated in CFD analysis for the M1, M2 and M3 models. Then the intermediate WIAs are plotted in their respective graphs. Finally, the

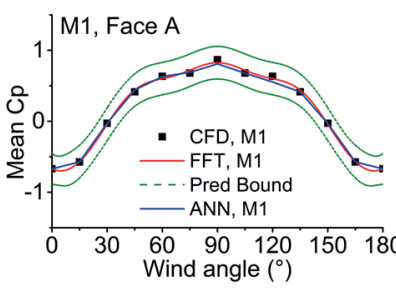

(a)

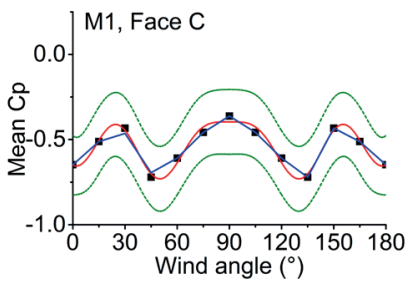

(c)

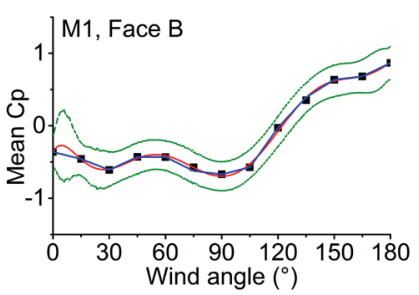

(b)

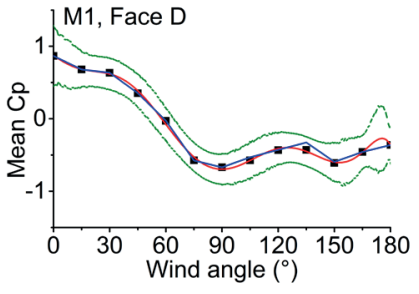

(d)
Fig. 8 Comparative study of pressure coefficient between CFD, FFT and ANN on M1 model for different WIAs (a) face A, (b) face B, (c) face $\mathrm{C}$ and (d) face D

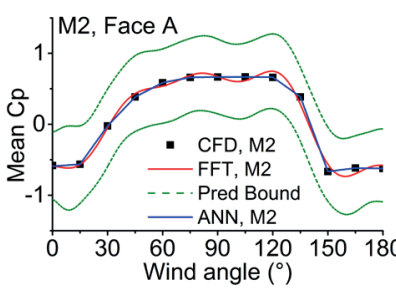

(a)

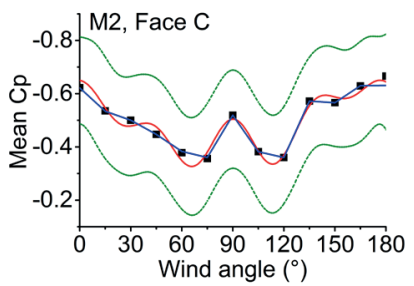

(c)

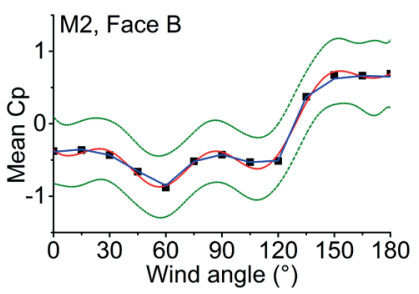

(b)

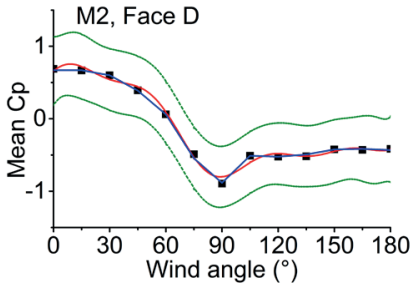

(d)
Fig. 9 Comparative study of pressure coefficient between CFD, FFT and ANN on M2 model for different WIAs (a) face A, (b) face B, (c) face $C$ and (d) face D 


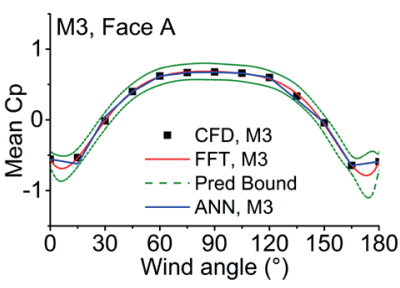

(a)

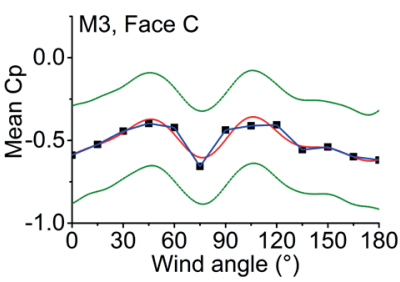

(c)

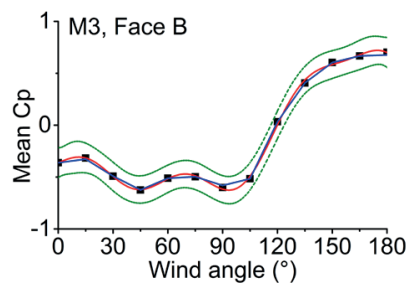

(b)

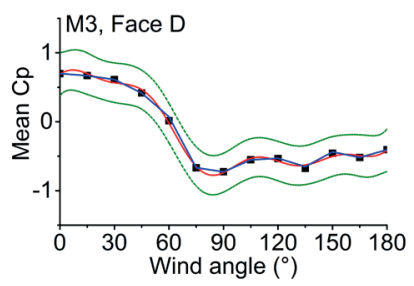

(d)
Fig. 10 Comparative study of pressure coefficient between CFD, FFT and ANN on M3 model for different WIAs (a) face A, (b) face B, (c) face $\mathrm{C}$ and (d) face D

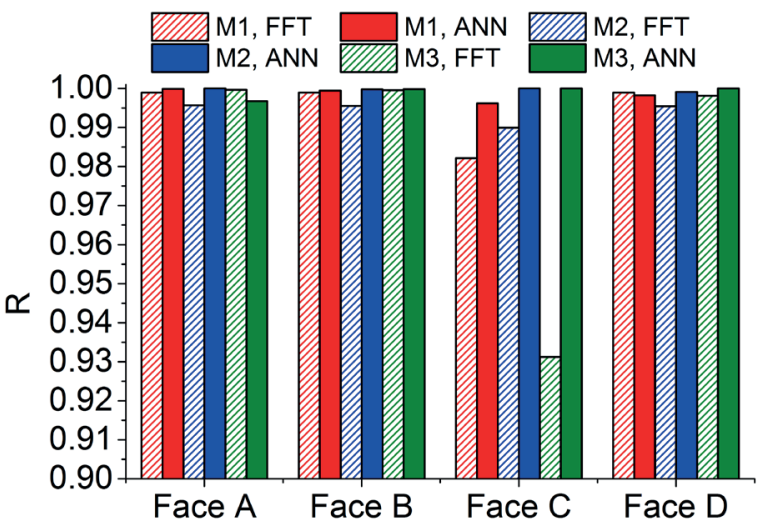

Fig. 11 Comparative studies of R between FFT and ANN method on face A, B, C and D

calculated $C_{p}$ of the particular models for their respective WIAs and errors are shown in Table 2. The train neural network exhibit the $C_{p}$ which almost the same as CFD. Whereas the $C_{p}$ from FFT has a large amount of fluctuation. Especially, model M1 has $12.76 \%$ and $13.63 \%$ errors on $\mathrm{C}$ and $\mathrm{D}$ faces, the M2 model has $30.1 \%$ and $16.67 \%$ errors on A and B faces for WIA $25^{\circ}$. Another interesting high percentage of errors $21.62 \%$ and $42.68 \%$ observed at face B and A for WIA $145^{\circ}$ on M2 and M3 models, respectively. The ANN model has a $0.18 \%$ to $2.5 \%$ error, which is highly negligible. Finally, the major points are, the ANN method supply more accurate result compared to the FFT method and the face wise pressure coefficient graph easily solved the intermediate pressure coefficient result of 1:1:2 $(l: b: h)$ model.
Table 2 Comparison of pressure coefficient errors between CFD, FFT and ANN for WIAs $25^{\circ}$ and $145^{\circ}$

\begin{tabular}{|c|c|c|c|c|c|c|}
\hline WIA & Model & Face name & A & B & $\mathrm{C}$ & D \\
\hline \multirow{15}{*}{$25^{\circ}$} & \multirow{5}{*}{ M1 } & CFD & 0.645 & -0.563 & -0.480 & -0.209 \\
\hline & & FFT & 0.644 & -0.600 & -0.411 & -0.241 \\
\hline & & ANN & 0.649 & -0.558 & -0.480 & -0.210 \\
\hline & & $\begin{array}{c}\text { FFT } \\
\text { error (\%) }\end{array}$ & 0.237 & 6.659 & 12.760 & 13.632 \\
\hline & & $\begin{array}{c}\text { ANN } \\
\text { error (\%) }\end{array}$ & 0.642 & 0.746 & 1.756 & 1.020 \\
\hline & \multirow{5}{*}{ M2 } & CFD & -0.2052 & -0.419 & -0.520 & 0.622 \\
\hline & & FFT & -0.2669 & -0.3488 & -0.4822 & 0.595 \\
\hline & & ANN & -0.2029 & -0.4143 & -0.5114 & 0.624 \\
\hline & & $\begin{array}{c}\text { FFT } \\
\text { error (\%) }\end{array}$ & 30.091 & 16.664 & 7.285 & 4.774 \\
\hline & & $\begin{array}{c}\text { ANN } \\
\text { error (\%) }\end{array}$ & 1.100 & 1.032 & 1.660 & 0.179 \\
\hline & \multirow{5}{*}{ M3 } & CFD & -0.177 & -0.457 & -0.4708 & 0.6310 \\
\hline & & FFT & -0.1888 & -0.4341 & -0.4826 & 0.5951 \\
\hline & & ANN & -0.1783 & -0.4475 & -0.4760 & 0.6309 \\
\hline & & $\begin{array}{c}\text { FFT } \\
\text { error }(\%)\end{array}$ & 6.671 & 4.992 & 2.203 & 7.457 \\
\hline & & $\begin{array}{c}\text { ANN } \\
\text { error (\%) }\end{array}$ & 0.738 & 2.060 & 0.814 & 1.891 \\
\hline \multirow{15}{*}{$145^{\circ}$} & \multirow{5}{*}{ M1 } & CFD & 0.645 & -0.563 & -0.480 & -0.209 \\
\hline & & FFT & 0.644 & -0.600 & -0.411 & -0.241 \\
\hline & & ANN & 0.649 & -0.558 & -0.480 & -0.210 \\
\hline & & $\begin{array}{c}\text { FFT } \\
\text { error }(\%)\end{array}$ & 0.237 & 6.659 & 12.760 & 13.632 \\
\hline & & $\begin{array}{c}\text { ANN } \\
\text { error (\%) }\end{array}$ & 0.642 & 0.746 & 1.756 & 1.020 \\
\hline & \multirow{5}{*}{ M2 } & CFD & -0.317 & 0.533 & -0.576 & -0.449 \\
\hline & & FFT & -0.327 & 0.649 & -0.594 & -0.482 \\
\hline & & ANN & -0.315 & 0.539 & -0.568 & -0.44697 \\
\hline & & $\begin{array}{c}\text { FFT } \\
\text { error (\%) }\end{array}$ & 3.087 & 21.622 & 3.142 & 7.538 \\
\hline & & $\begin{array}{c}\text { ANN } \\
\text { error (\%) }\end{array}$ & 0.599 & 1.064 & 1.343 & 0.354 \\
\hline & \multirow{5}{*}{ M3 } & CFD & 0.0677 & 0.5489 & -0.5370 & -0.5216 \\
\hline & & FFT & 0.0966 & 0.5540 & -0.5410 & -0.5477 \\
\hline & & ANN & 0.0666 & 0.5382 & -0.5442 & -0.5086 \\
\hline & & $\begin{array}{c}\text { FFT } \\
\text { error }(\%)\end{array}$ & 42.68 & 0.925 & 0.745 & 5.009 \\
\hline & & $\begin{array}{c}\text { ANN } \\
\text { error (\%) }\end{array}$ & 1.549 & 1.940 & 1.345 & 2.489 \\
\hline
\end{tabular}




\subsection{Comparison of drag and lift coefficient}

The drag and lift coefficient for $0^{\circ}$ to $180^{\circ}$ WIAs at $15^{\circ}$ intervals by CFD analysis, ANN method and the error between CFD and ANN presented in Fig. 12. The drag coefficient equation explained by Simiu and Scanlan [51] reflected in Eq. (20).

$$
F_{D}(t)=\frac{1}{2} \rho v^{2}(t) B^{2} C_{d}
$$

where $F_{D}(t)$ is the time-varying drag on a body, $\rho$ is the density of the fluid, $v(t)$ is the speed of the object relative to the fluid varying with time, $B$ is the typical body dimension and $C_{d}$ is the drag coefficient. Drag and lift coefficients are marked as $C_{f x}$ and $C_{f y}$ in this study and computed by the CFD method shown in Figs. 12(a) and (d). Only the drag and lift coefficient of CFD and ANN method presented here. After that, the neural network method applied to evaluate the $C_{f x}$ and $C_{f y}$ as shown in Figs. 12(b) and (e) respectively. The WIAs considered as input data then $C_{f x}$ and $C_{f y}$ used as training data. Both the CFD and ANN results are presented appreciable results. The error of $C_{f x}$ and $C_{f y}$ between CFD and ANN methods presented in Figs. 12(c) and (f) respectively. The regression plot and error distribution of training samples for drag and lift coefficient for the M1, M2 and M3 models presented in
Fig. 13 and Fig. 14, respectively. The coefficient of correlation has an appreciable value greater than 0.999 for all the training data. The percentage of error for drag and lift coefficient (vertical column in Fig. 14) reflected the high accuracy of the ANN method.

\section{Conclusions}

The graphical presentation of pressure coefficient for $0^{\circ}$ to $180^{\circ} \mathrm{WIAs}$ at $15^{\circ}$ intervals are estimated by CFD, FFT and ANN methods. The comparative study between those methods are quite interesting and the ANN method reflects the high accuracy of the result, which perfectly matched with the CFD study with less percentage of error. The correlation coefficient reflected the amount of accuracy between the FFT and ANN methods. Furthermore, two intermediate angles $25^{\circ}$ and $145^{\circ}$ WIAs used to check the accuracy of the graph. This reflects the $0.18 \%$ to $2.5 \%$ errors for the ANN method but the FFT method has a maximum $42.7 \%$ error. Similarly, less percentage of error for drag and lift coefficient standardized the efficiency of the ANN method. According to this face wise graphs, the pressure coefficient at any intermediate angles of the 1:1:2 $(l: b: h)$ model can be easily estimated. The accuracy of the result increase with the increase of input and training data in the ANN method.

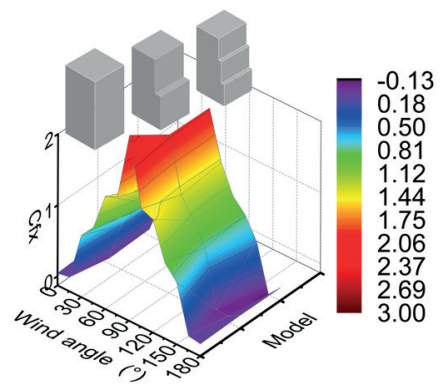

(a)

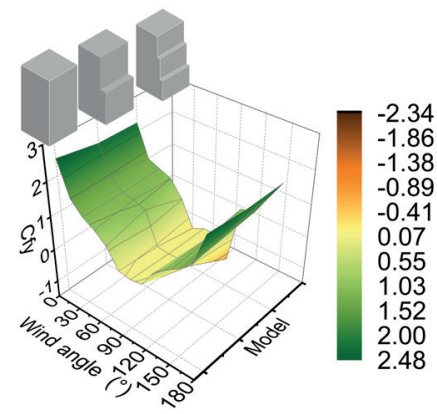

(d)

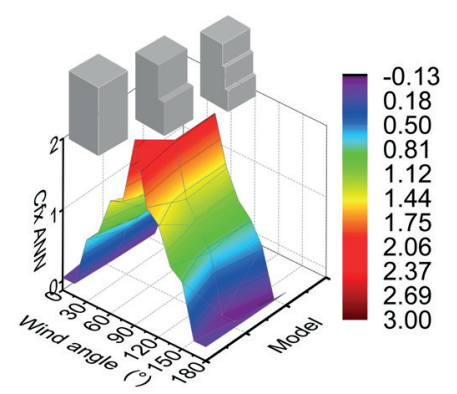

(b)

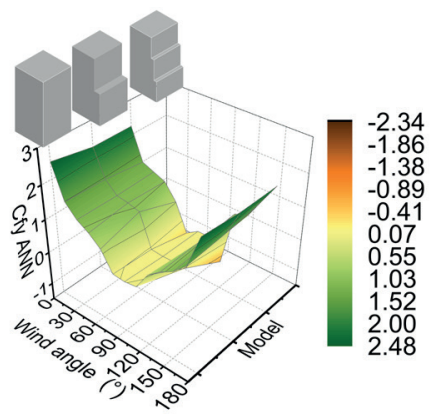

(e)

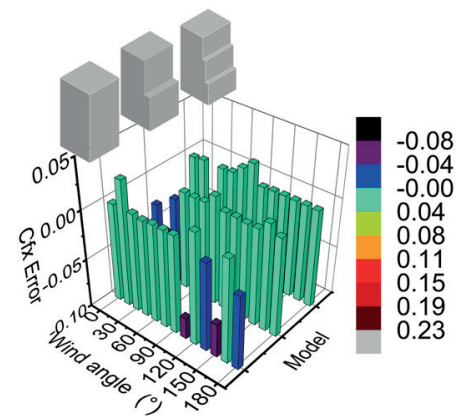

(c)

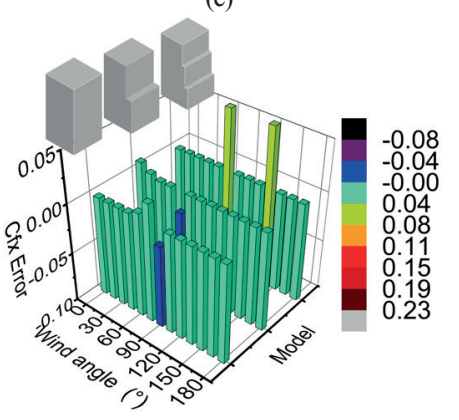

(f)

Fig. 12 Surface plot of drag and lift coefficient of M1, M2 and M3 models for (a) and (d) CFD method, (b) and (e) ANN method respectively. Percentage of error between CFD and ANN method (c) for drag and (f) for lift coefficient 
(a)
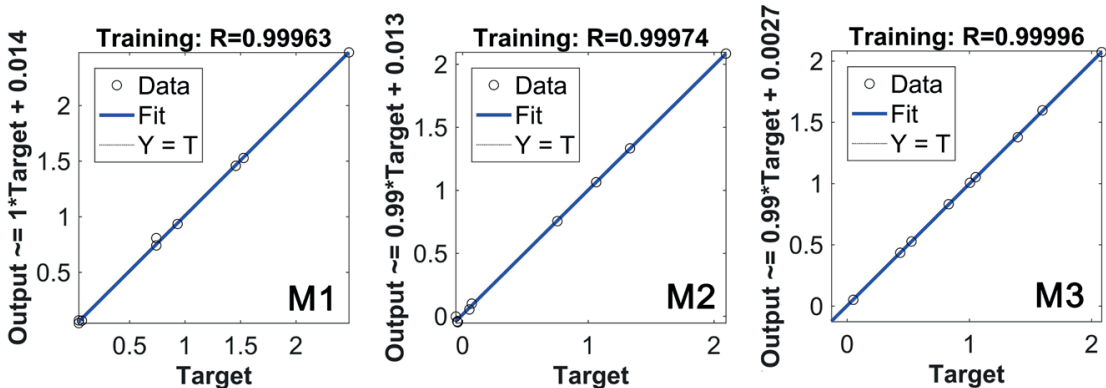

(b)
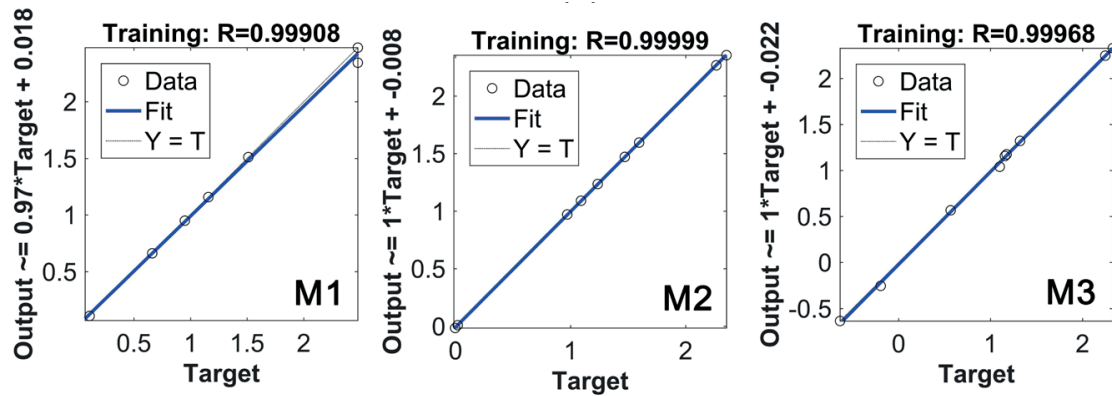

Fig. 13 Regression plots of 15 neurons training samples for M1, M2 and M3 models due to (a) drag coefficient and (b) lift coefficient

Drag
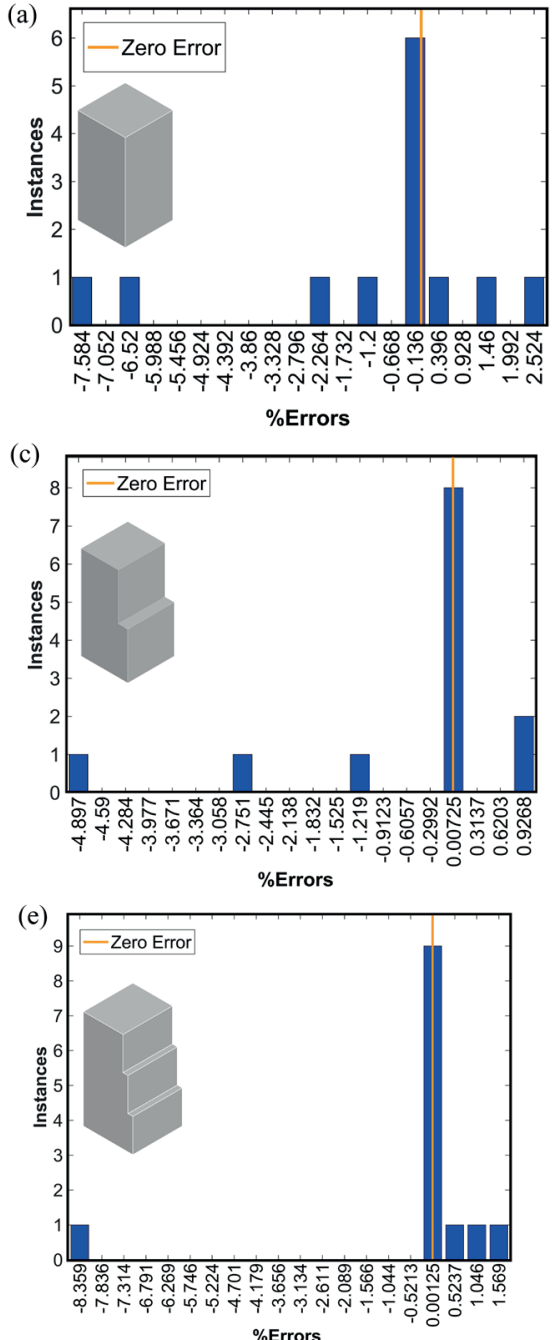

Lift

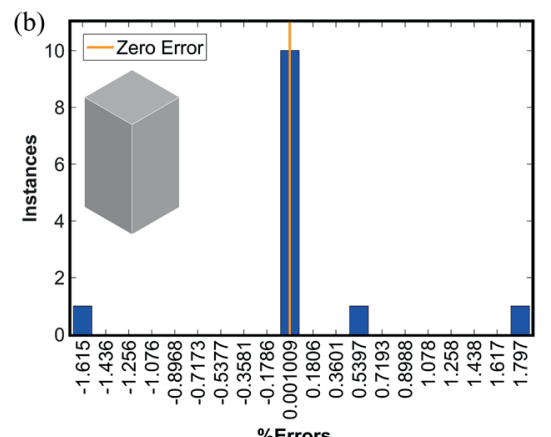

(d)
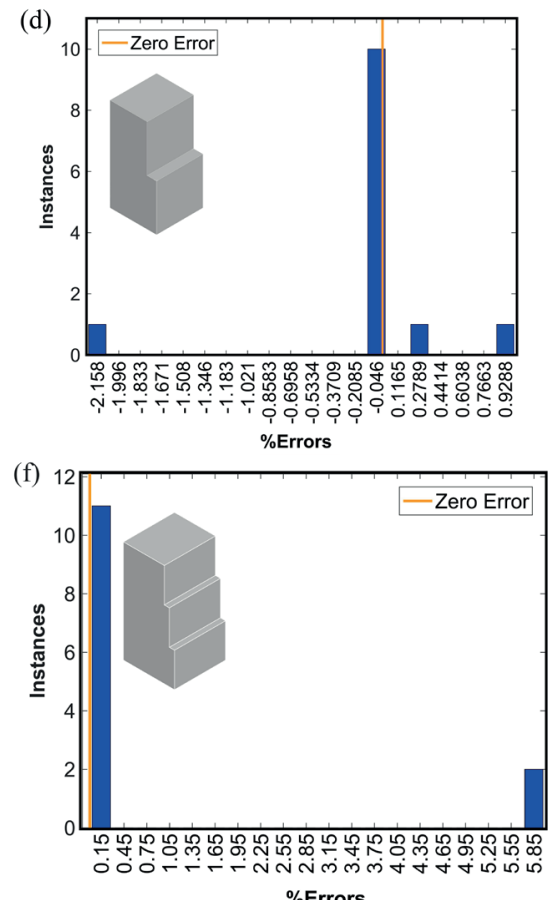

Fig. 14 Error distribution of drag (a, c, and e) and lift (b, d, and f) for M1, M2 and M3 models 


\section{References}

[1] Kim, Y. C., Kanda, J., Tamura, Y. "Wind-induced coupled motion of tall buildings with varying square plan with height", Journal of Wind Engineering and Industrial Aerodynamics, 99(5), pp. 638$650,2011$.

https://doi.org/10.1016/j.jweia.2011.03.004

[2] Tanaka, H., Tamura, Y., Ohtake, K., Nakai, M., Kim, Y. C. "Experimental investigation of aerodynamic forces and wind pressures acting on tall buildings with various unconventional configurations", Journal of Wind Engineering and Industrial Aerodynamics, 107-108, pp. 179-191, 2012.

https://doi.org/10.1016/j.jweia.2012.04.014

[3] Bairagi, A. K., Dalui, S. K. "Optimization of Interference Effects on High-Rise Building for Different Wind Angle Using CFD Simulation", Electronic Journal of Structural Engineering, 14, pp. 39-49, 2014. [online] Available at: http:/www.ejse.org/Archives/ Fulltext/2014/2014-5.pdf

[4] Roy, K., Kumar Bairagi, A. "Wind pressure and velocity around stepped unsymmetrical plan shape tall building using CFD simulation - A case study", Asian Journal of Civil Engineering, 17(8), pp. 1055-1075, 2016.

[5] Elshaer, A., Aboshosha, H., Bitsuamlak, G., Damatty, A. E., Dagnew, A. "LES evaluation of wind-induced responses for an isolated and a surrounded tall building", Engineering Structures, 115, pp. 179-195, 2016.

https://doi.org/10.1016/j.engstruct.2016.02.026

[6] Cui, W., Caracoglia, L. "Examination of experimental variability in HFFB testing of a tall building under multi-directional winds", Journal of Wind Engineering and Industrial Aerodynamics, 171, pp. 34-49, 2017.

https://doi.org/10.1016/j.jweia.2017.09.001

[7] Li, Y., Tian, X., Tee, K. F., Li, Q.-S., Li, Y.-G. "Aerodynamic treatments for reduction of wind loads on high-rise buildings", Journal of Wind Engineering and Industrial Aerodynamics, 172, pp. 107115, 2018.

https://doi.org/10.1016/j.jweia.2017.11.006

[8] Bairagi, A. K., Dalui, S. K. "Comparison of aerodynamic coefficients of setback tall buildings due to wind load", Asian Journal of Civil Engineering, 19, pp. 205-221, 2018. https://doi.org/10.1007/s42107-018-0018-3

[9] Bairagi, A. K., Dalui, S. K. "Aerodynamic Effects on Setback Tall Building Using CFD Simulation", International Journal of Mechanical and Production Engineering Research and Development, pp. 413-420, 2018.

[10] Bairagi, A. K., Dalui, S. K. "Comparison of pressure coefficient between square and setback tall building due to wind load", presented at SEC18: Proceedings of the 11th Structural Engineering Convention - 2018, Kolkata, India, Dec, 19-21, 2018.

[11] Rajasekarababu, K. B., Vinayagamurthy, G., Selvi Rajan, S. "Experimental and computational investigation of outdoor wind flow around a setback building", Building and Simulation, 12, pp. 891-904, 2019. https://doi.org/10.1007/s12273-019-0514-8

[12] Bitsuamlak, G. T., Bédard, C., Stathopoulos, T. "Modeling the Effect of Topography on Wind Flow Using a Combined Numerical-Neural Network Approach", Journal of Computing in Civil Engineering, 21(6), 2007.

https://doi.org/10.1061/(ASCE)0887-3801(2007)21:6(384)
[13] Wang, J, Cheng, C.-M. "The Application of Artificial Neural Networks to Predict Wind Spectra for Rectangular Cross-Section Buildings", presented at The Fifth International Symposium on Computational Wind Engineering (CWE2010), Chapel Hill, NCNorth Carolina, USA, May, 23-27, 2010.

[14] Verma, S. K., Kumar, K., Kaur, H. "Estimation of Coefficient of Pressure in High Rise Buildings Using Artificial Neural Network", International Journal of Engineering Research and Applications, 4(4), pp. 105-110, 2014.

[15] Elshaer, A., Bitsuamlak, G., Damatty, A. E. "Aerodynamic optimization to reduce wind loads on tall buildings", presented at Resilient Infrastructure, London, ON, Canada, June, 1-4, 2016.

[16] Kar, R., Dalui, S. K., Bhattacharjya, S. "An efficient optimization approach for wind interference effect on octagonal tall building", Wind and Structures, 28(2), pp. 111-128, 2019.

https://doi.org/10.12989/was.2019.28.2.111

[17] Balogh, B., Lógó, J. "Optimal design of curved folded plates", Periodica Polytechnica Civil Engineering, 58(4), pp. 423-430, 2014.

https://doi.org/10.3311/PPci.7856

[18] Kaveh, A., Kooshkbaghi, M. "Enhanced Artificial Coronary Circulation System Algorithm for Truss Optimization with Multiple Natural Frequency Constraints", Periodica Polytechnica Civil Engineering, 63(2), pp. 362-376, 2019. https://doi.org/10.3311/PPci.13562

[19] Dhote, S. U., Varghese, V. "Application of Artificial Neural Network in Wind Response of Tall Buildings", International Journal of Engineering Research in Mechanical and Civil Engineering, 3(1), pp. 164-167, 2018 .

https://doi.org/01.1617/vol5/iss1/pid53947

[20] BIS "IS:875(Part-3): Wind Loads on Buildings and StructuresProposed Draft \& Commentary", Bureau of Indian Standards, New Delhi, India, 2015.

[21] Elshaer, A., Bitsuamlak, G. "Multiobjective Aerodynamic Optimization of Tall Building Openings for Wind-Induced Load Reduction", Journal of Structural Engineering, 144(10), Article number: 04018198, 2018. https://doi.org/10.1061/(ASCE)ST.1943-541X.0002199

[22] Bhattacharyya, B., Dalui, S. K. "Investigation of mean wind pressure on 'E' plan shape tall building", Wind and Structure, 26(2), pp. 99-114, 2018.

https://doi.org/10.12989/was.2018.26.2.099

[23] Kaveh, A., Iranmanesh, A. "Comparative Study of Backpropagation and Improved Counterpropagation Neural Nets in Structural Analysis and Optimization", International Journal of Space Structures, 13(4), pp. $177-185,1998$. https://doi.org/10.1177/026635119801300401

[24] Iranmanesh, A., Kaveh, A. "Structural optimization by gradient base neural networks", International Journal of Numerical Methods in Engineering, 46(2), pp. 297-311, 1999. https://doi.org/10.1002/(SICI)1097-0207(19990920)46:2<297:: AID-NME679>3.0.CO;2-C

[25] Kaveh, A., Khalegi, A. "Prediction of strength for concrete specimens using artificial neural network", Asian Journal of Civil Engineering, 2(2), pp. 1-13, 2000. https://doi.org/10.4203/ccp.53.4.3 
[26] Kaveh, A., Dehkordi, F., Servati, H. "Prediction of moment-rotation characteristic for saddle-like connections using BP neural networks", Asian Journal of Civil Engineering, 1(2), pp. 11-30, 2001.

[27] Rofooei, F. R., Kaveh, A., Farahani, F. M. "Estimating the vulnerability of concrete moment resisting frame structures using artificial neural networks", International Journal of Optimization in Civil Engineering, 1(3), pp. 433-448, 2011.

[28] Paral, A., Singha Roy, D. K., Samanta, A. K. "Application of a mode shape derivative-based damage index in artificial neural network for structural damage identification in shear frame building", Journal of Civil Structural Health Monitoring, 9, pp. 411-423, 2019. https://doi.org/10.1007/s13349-019-00342-x

[29] Kaveh, A., Servati, H. "Design of double layer grids using back-propagation neural networks", Computers and Structures, 79(17), pp. 1561-1568, 2001. https://doi.org/10.1016/S0045-7949(01)00034-7

[30] Kaveh, A., Gholipour, Y., Rahami, H. "Optimal Design of Transmission Towers Using Genetic Algorithm and Neural Networks", International Journal of Space Structures, 23(1), pp. 1-19, 2008. https://doi.org/10.1260/026635108785342073

[31] Fernández-Cabán, P. L., Masters, F. J., Phillips, B. M. "Predicting Roof Pressures on a Low-Rise Structure from Freestream Turbulence Using Artificial Neural Networks", Frontiers in Built Environment, 4(68), 2018. https://doi.org/10.3389/fbuil.2018.00068

[32] Nikose, T. J., Sonparote, R. S. "Dynamic wind response of tall buildings using artificial neural Network", The Structural Design of Tall and Special Building, 28(13), Article number: 1657, 2019. https://doi.org/10.1002/tal.1657

[33] Nikose, T. J., Sonparote, R. S. "Dynamic along wind response of tall buildings using Artificial Neural Network", Cluster Computing, 22, pp. 3231-3246, 2019. https://doi.org/10.1007/s10586-018-2027-0

[34] Mallick, M., Mohanta, A., Kumar, A., Patra, K. C. "Prediction of Wind-Induced Mean Pressure Coefficients Using GMDH Neural Network", Journal of Aerospace Engineering, 33(1), 2020. https://doi.org/10.1061/(ASCE)AS.1943-5525.0001101

[35] Jones, W. P., Launder, B. E. "The prediction of laminarization with a two-equation model of turbulence", International Journal of Heat and Mass Transfer, 15(2), pp. 301-314, 1972. https://doi.org/10.1016/0017-9310(72)90076-2

[36] Franke, J., Hirsch, C., Jensen, A. C., Krüs, H. W., Schatzmann, M., Westbury, P. S., Miles, S. D., Wisse, J. A., Wright, N. G. "Recommendations on the use of CFD in wind engineering", presented at COST Action C14, Impact of Wind and Storm on City Life and Built Environment, Von Karman Institute for Fluid Dynamics, Rhode-Saint-Genèse, Belgium, May, 5-7, 2004.

[37] Revuz, J., Hargreaves, D. M., Owen, J. S. "On the domain size for the steady-state CFD modelling of a tall building", Wind and Structures, 15(4), pp. 313-329, 2012. https://doi.org/10.12989/was.2012.15.4.313

[38] BIS "SP 64:2001 Explanatory handbook on Indian standard code of practice for design loads (other than earthquake) for buildings and structures", Bureau of Indian Standards, New Delhi, India, 2001
[39] Franke, J., Hellsten, A., Schlünzen, H., Carissimo, B. (eds.) "Best practice guideline for the CFD simulation of flows in the urban environment", COST Action 732, Brussels, Belgium, 2007.

[40] Tominaga, Y., Mochida, A., Yoshie, R., Kataoka, H., Nozu, T., Yoshikawa, M., Shirasawa, T. "AIJ guidelines for practical applications of CFD to pedestrian wind environment around buildings", Journal of Wind Engineering and Industrial Aerodynamics, 96(1011), pp. 1749-1761, 2008. https://doi.org/10.1016/j.jweia.2008.02.058

[41] Kim, Y., Kanda, J. "Characteristics of aerodynamic forces and pressures on square plan buildings with height variations", Journal of Wind Engineering and Industrial Aerodynamics, 98(8-9), pp. 449465, 2010. https://doi.org/10.1016/j.jweia.2010.02.004

[42] Meng, Y., Hibi, K. "Turbulent measurements of the flow field around a high-rise building", Journal of Wind Engineering, 76, pp. 55-64, 1998. (in Japanese) https://doi.org/10.5359/jawe.1998.76_55

[43] Wang, D., Yu, X. J., Zhou, Y., Tse, K. T. "A combination method to generate fluctuating boundary conditions for large eddy simulation", Wind and Structures, 20(4), pp. 579-607, 2015. https://doi.org/10.12989/was.2015.20.4.579

[44] Tominaga, Y., Mochida, A., Murakami, S., Sawaki, S. "Comparison of various revised $\mathrm{k}-\varepsilon$ models and LES applied to flow around a high-rise building model with 1:1:2 shape placed within the surface boundary layer", Journal of Wind Engineering and Industrial Aerodynamics, 96(4), pp. 389-411, 2008. https://doi.org/10.1016/j.jweia.2008.01.004

[45] Gousseau, P., Blocken, B., van Heijst, G. J. F. "Quality assessment of Large-Eddy Simulation of wind flow around a high-rise building: Validation and solution verification", Computers \& Fluids, 79, pp. 120-133, 2013 https://doi.org/10.1016/j.compfluid.2013.03.006

[46] Haykin, S. "Neural Networks and Learning Machines", 3rd ed., Pearson Education, Inc., Upper Saddle River, NJ, USA, 2009.

[47] Kaveh, A., Raissi Dehkordi, M. "Neural Networks for the Analysis and Design of Domes", International Journal of Space Structures, 18(3), pp. 181-194, 2003. https://doi.org/10.1260/026635103322437463

[48] Demuth, H., Beale, M. "Neural Network Toolbox For Use with MATLAB", User's Guide, Version 4, The Math Works, Inc., Natick, MA, USA, 2004.

[49] Beale, M. H., Hagan, M. T., Demuth, H. B. "Neural Network Toolbox 7 User's Guide", Version 7.0, The Math Works, Inc., MA, USA, 2010.

[50] Hunter, D., Yu, H., Pukish, M. S., Kolbusz, J., Wilamowski, B. M., "Selection of Proper Neural Network Sizes and Architectures - A Comparative Study", IEEE Transactions on Industrial Informatics, 8(2), pp. 228-240, 2012. https://doi.org/10.1109/TII.2012.2187914

[51] Simiu, E., Scanlan, R. H. "Wind Effects on Structures: Fundamentals and Applications to Design", 3rd ed., Wiley \& Sons, New York, NY, USA, 1996. 